\title{
Usability problems and literacy of online maps
}

\author{
Shin MURAKOSSHI ${ }^{\mathrm{a},}{ }^{*}$, Kenta MITSUSHITA $^{\mathrm{b}}$ \\ ${ }^{a}$ Faculty of Education, Shizuoka University, murakoshi.shin@shizuoka.ac.jp \\ ${ }^{b}$ Graduate School of Education, Shizuoka University, mitsushita.kenta.16@shizuoka.ac.jp \\ * Corresponding author
}

\begin{abstract}
The purpose of the current research is to identify usability problems of online maps and examine literacy complementary to the problems from a viewpoint of real-world problem solving discussed in Saeki (1988) and Harada (1997). In an experiment, a route search task and a task to select a safer place to live in by using hazard maps and a security map were given to seven students, a researcher of geography and two researchers of natural disaster prevention. As a result, 62 usability problems were identified at three levels: operation/perception load, understanding operation and display, and formation of operational intention and practical interpretation. The use of existing knowledge and strategies for smooth problem solving were also found. Online map literacy was discussed based on the results.
\end{abstract}

Keywords: usability, online maps, literacy, hazard maps, security maps

\section{Introduction}

Although online maps were evaluated as being easier to use than paper maps, the rate of online map users was $69.43 \%$ whereas that of paper map users was $84.07 \%$ in a survey of university students conducted in 2005, when smartphones were not common (Murakoshi, 2006). Now that smartphones have become common and the functionality of online maps has improved, the rate of online map users was $57.8 \%$ for those who use online maps on personal computers and $48.8 \%$ for those who use them on smartphones, whereas the rate of paper map users was 21.4\% (Zenrin, 2018).

Convenient features of online maps compared to paper maps were pointed out as: pinpoint searches, seamless movement across screens, serial scale changes, and multilayer structure (Wakabayashi, 2018). In addition, online maps are interactive and only necessary information can be displayed. Online maps can also be used whenever necessary if an internet environment is provided with virtually no cost. As a result, usage of multipurpose paper maps is dependent on attributes of users such as a sense of direction and liking and disliking for maps, but usage of digital maps was not dependent on attributes of users such as sex and completion of geography in high school (Okamoto, 2002; Wakabayashi, 2003). Murakoshi (2006) also reported that subjective usability was dependent on user attributes for paper maps but not for maps on computers or cellular phones. Online maps were easy to use among a larger population.

However, online maps share the same characteristics as paper maps to some extent. For example, a map consists of abstract expressions of symbols. Since the size of a map is regulated by scale, the extent of omission is dependent on the scale, and thus everything in the real world is not necessarily expressed on a map. If one is not familiar with regulations, one might fail to read a map correctly because of the "lie of the map," i.e., the difference from reality (Wakabayashi, 2018). Despite that online maps are easy to read for a larger population, some kind of literacy might be necessary in order to use the maps properly. In addition, since users can interact with online maps, understanding the background of the "lie of the map" and relevant interactions with online maps are necessary. Literacy of online maps, which might be different from that of paper maps, is demanded (Wakabayashi, 2018, p.201).

Researches on the usability of online maps have been conducted (e.g., Nivala, Brewster, \& Sarjokoski, 2008; Bishop, Haggerty, \& Richardson, 2015; Voldan, 2011; Çöltekin, Heil, Garlandini, \& Fabrikant, 2013), which identified quite a few usability problems, mostly search problems, but they generally involved interface or operation problems. On the contrary, there have not been enough researches as to usability from the viewpoint of real-world problem solving using online maps. Identifying usability problems of online maps enable reducing barriers to online maps, which might be used by a variety of users (Wakabayashi, 2003).

Herewith, the definition of the usability of the current study is introduced. Usability used to be a concept referring to characteristics of machines or software with which one can smoothly execute operations to attain designated goals. As to online maps, usability is dependent not only on the size or colors of symbols, patterns, which have been traditional themes for cartography, or easiness of physical operations, but it is also dependent on easiness of understanding operations to realize the users' intention. This can be interpreted as easiness of dialogue between users and machines/software (e.g., Norman, 1986). Now that PCs/digital devices have become easier to use, the concept of usability should be extended. As to an extended definition, Saeki's (1988) or Harada's (1997) concept of usability might be useful. They insist that usability should deal not only with users + machine, but also with users + 
machine + tasks, and that the real world in which a problem is solved should be considered. For example, if one is given a problem to find a safer place to live in with online maps, one should interpret "safer place" as an operational intention such as "searching for places of criminal occurrence" or "searching for areas suffering from natural disasters." One should also select and execute operations according to one's intention, which follows a proper perception and interpretation of display. The task is completed only after a relevant interpretation of the real world from a direct interpretation of display.

Figure 1 indicates the framework of usability problems from the viewpoint of users + online maps + real world tasks. The usability problems might be categorized into: problems at the interface between users and online maps/ $P C$ (operation and perception load), problems in dialog between online maps and users (selection of operation and interpretation of display), and problem in link between users + online map system and the real-world (formation of operational intention and practical interpretation), the last of which is original in the current study.

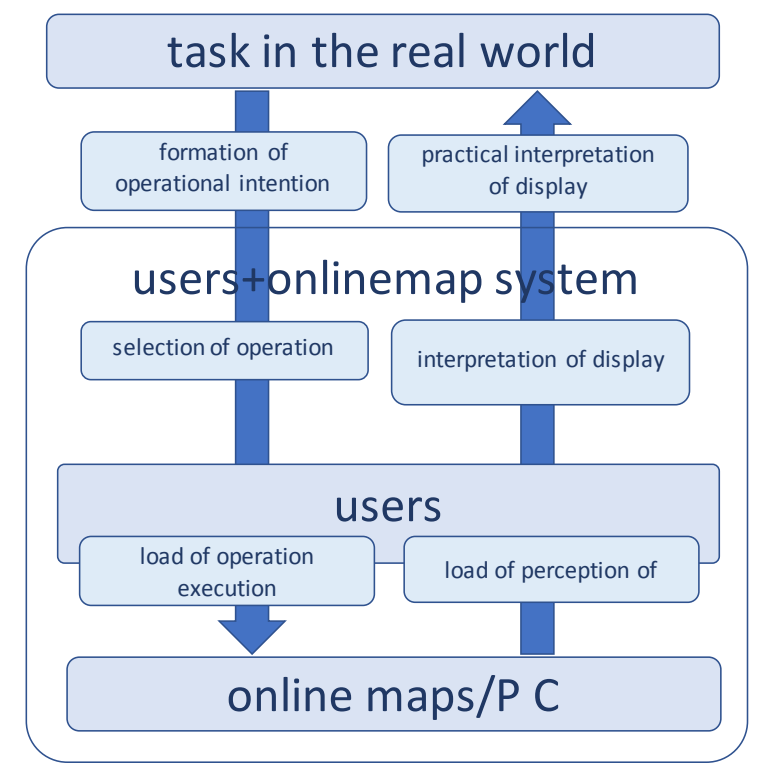

Figure 1. Framework of usability of the current study.

Defining usability from this viewpoint, the usability problems cannot be separated from literacy, which is synonymous with graphicacy in this context and defined as "the ability to understand and present information in the form of sketches, photographs, diagrams, maps, plans, charts, graphs and other non-textual, two-dimensional formats" (Aldrich \& Sheppard, 2000), because no matter how much information is displayed on online maps, usability is complemented by literacy so long as not all information is provided on a screen. Graphicacy broadly overlaps with the concept of spatial thinking (National Research Council, 2006).

\section{Purpose}

The purpose of the current study is to identify usability problems of online maps for real-world problem solving as well as to examine the literacy for online maps.

\section{Methods}

\subsection{Online maps used and tasks}

Two tasks were prepared. The scenario of the first task was route search for a short trip with Google Map from the designated start (JR Chiba Station) to the destination (Yoro hot spring), which are both in Chiba Prefecture. Direct required time was about $70 \mathrm{~min}$, and it is required to plan a trip within six hours by choosing one or two stopover(s) between the start and the destination. A printout of the result was also required.

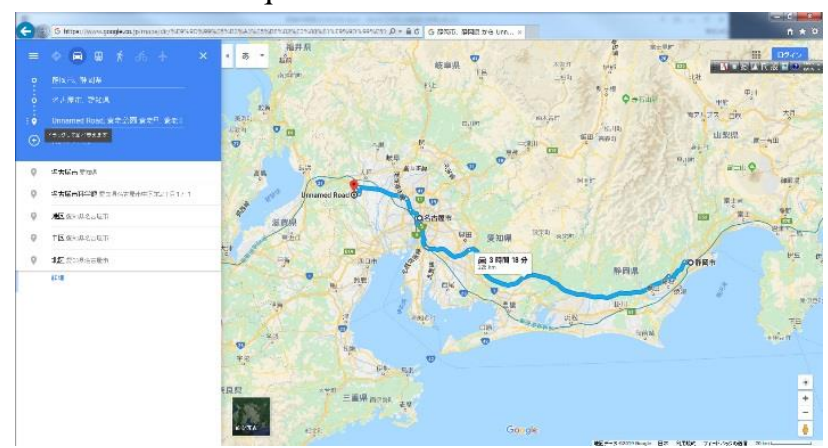

Figure 2. Search screen of Google Map used for the task 1.

The scenario of the second task was to select one from four designated resident sites in Takasaki City, Gunma Prefecture for a woman who will be moving to the city in order to start working as a primary school teacher. The city was selected because hazards of landslide/debris flow and flood are expected not so far from the city center as well as several expressions of security maps are provided. The designated sites are 1) Kataokamachi 3chome, 2) Shimokobanamachi, 3) Kuragano-cho, and 4) Maehakodamachi (actually situated in Maebashi City, next to Takasaki City).

Maps used are a hazard map portal (https://disaportal.gsi.go.jp/) and a security map (http://mapping-gunma.pref.gunma.jp/pref-

gunma/PositionSelect? mid= 1520), and only these two maps were allowed for solving the problem. From the top screen of the hazard map portal, two types of hazard maps, the "Layered hazard map" and "My town hazard maps" are linked. Address search is possible only in the Layered hazard map, and the scale and area can be seamlessly changed in the Layered hazard map whereas the PDF hazard maps are placed deeply in My town hazard maps, and it is necessary to follow some links in order to reach the PDF hazard maps. According to the hazard map, 1) Kataokamachi 3-chome and 2) Shimokobanamachi are situated in an area where floods are expected. In addition, debris flow from the south west hills is expected to come near 1). However, default display of hazards in the Layered hazard map is limited for first-grade rivers and 2) Shimokobanamachi is situated in a wetlands of a secondgrade river flood area, which is not displayed.

Address search is possible in the security map. Sites of snatching incidents and observation of suspicious persons who might commit crimes against children and 
women were displayed by default. Criminal density such as residence intrusion and collective occurrence by town and area can be displayed by buttons. Suspicious persons who might commit crimes against children can be seen at all four sites but suspicious persons who might commit crimes against women can be seen only near 3) Kuraganocho. Default display of criminal occurrence is for 2018, but this can be changed from 2015 to 2018; collective occurrence for all four years cannot be displayed.
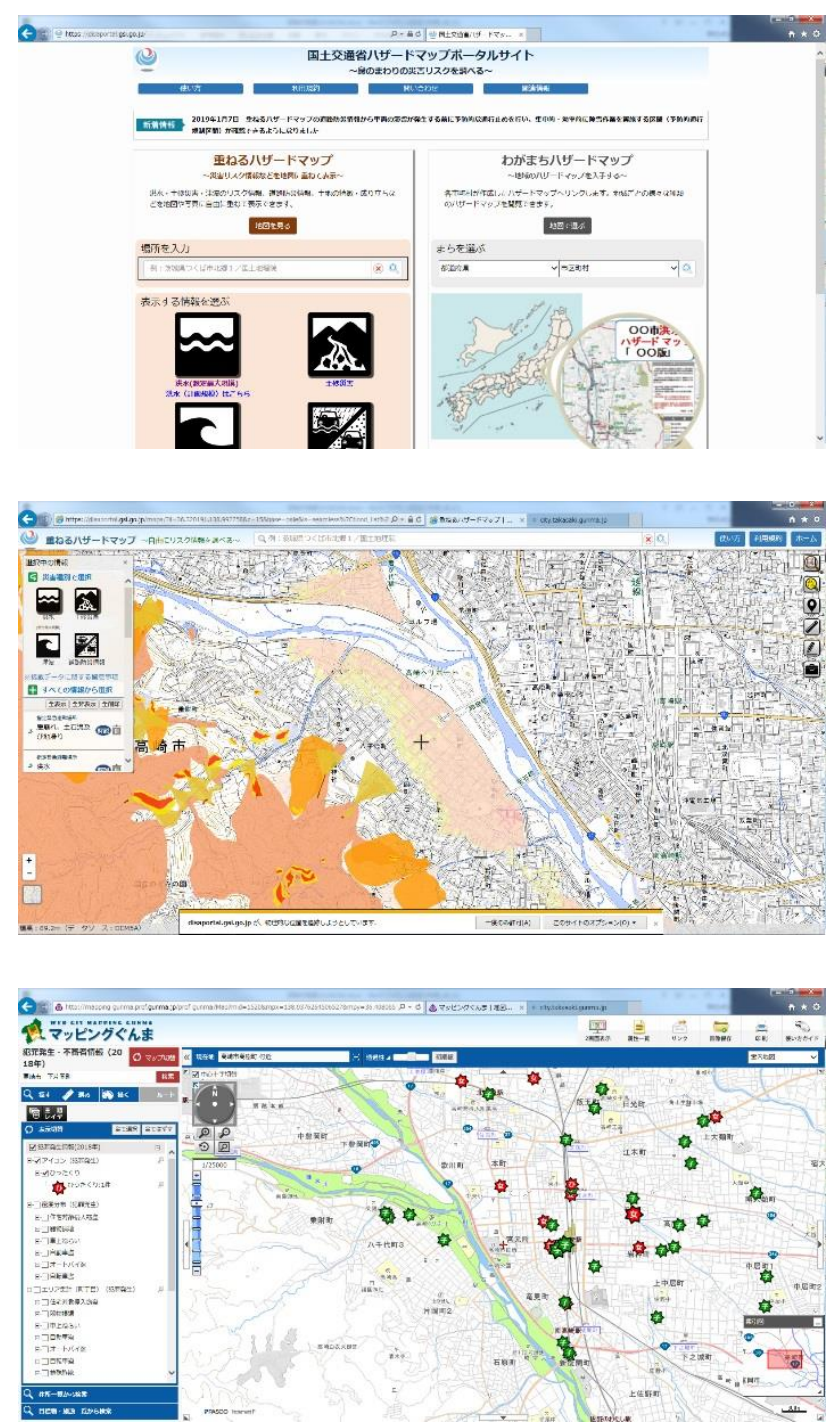

Figure 3. Hazard maps and Security map used for task 2. From the top to the bottom; Main screen of the hazard map portal, in which the Layered Hazard Map (left) and My Town Hazard maps (right) are linked, display of debris flow and flood of the Layered Hazard Map, and default display of snatching incidents and observation of suspicious persons who might commit crimes against children and women.

\subsection{Procedure}

After explaining the outline of the experiment, and treatment of individual information, a written agreement of participation was obtained. Face sheet items were asked: age, years of PC and online map usage, experience with Google Map, hazard map sites, and security maps, liking or disliking for maps, whether good at using maps, etc.
Time limitation for task one was 15 minutes, and that for task two was 30 minutes. If one got into trouble solving tasks, e.g., continuing to solve the problem with the wrong search result, correction was given. The operations of online maps were recorded by screen capture software. After the task, free-answer questions were given such as, experience with a similar task, whether they could do as they planned, difficult points, barrier to use etc. The current article reports the content of the free answers.

\subsection{Participants}

The participants were seven university students of education, two researchers of disaster prevention, and one researcher of geography. Although the number of participants was limited, a variety of usability problems were obtained as a preliminary study.

\section{Results}

\subsection{Face sheet items}

Years of PC and online map usage for the researchers was 26.7 years and 13.3 years, respectively. All of them had experience with Google Map and hazard maps, but none of them had experience with security maps. All of them like to use maps and were good at using maps. Years of PC and online map usage for the seven students were 4.6 years and 3 years, respectively. All but one have experience with Google Map but only one had experience of using hazard maps. None of them have ever used security maps. All but two rather dislike or dislike using maps, and all but one were not good at using maps.

\subsection{Reported usability problems}

The number of reported usability problems was 62. Same problems from one participant were counted as one. The result of categorization according to the framework explained in the introduction is shown in Table 1. Twentysix problems were pointed out for Google Map and certain numbers of problems were also pointed out for the security map, the Layered hazard map, and My town hazard map. As to the process of map use, many problems were reported for operation/perception load and practical interpretation of display as well as selection of operation, which numbered 17. Typical examples are shown in Table 2 .

\subsection{Literacy}

There were 35 reports which could be interpreted as exhibition of literacy (Table 3). They consisted of use of existing knowledge, inference using the knowledge, and strategies in use of reaction from the maps. Most of the items were from and related to the real world; 10 out of this were categorized as formation of operational intention, and 13 as practical interpretation of display. Nine items were categorized as selection of operation, in which relatively many items were categorized as support by existing knowledge from other software, and use of reaction from the maps. Typical examples are shown in Table 4. 


\begin{tabular}{lcccccc}
\hline Cognitive process of task & total & Google map & $\begin{array}{c}\text { Criminal } \\
\text { map }\end{array}$ & $\begin{array}{c}\text { Layered } \\
\text { hazard map }\end{array}$ & $\begin{array}{c}\text { My town } \\
\text { hazard map }\end{array}$ & $\begin{array}{c}\text { not } \\
\text { specified }\end{array}$ \\
\hline formation of operational intention & 3 & 0 & 3 & 0 & 0 & 0 \\
selection of operation & 17 & 12 & 1 & 3 & 1 & 0 \\
load of operation execution & 20 & 9 & 4 & 0 & 4 & 3 \\
load of perception of map reaction & 0 & 0 & 0 & 0 & 0 & 0 \\
interpretation of display & 20 & 4 & 6 & 6 & 2 & 2 \\
practical interpretation of display & 2 & 1 & 0 & 0 & 0 & 1 \\
Others & 62 & 26 & 14 & 9 & 7 & 6 \\
\hline Total & & &
\end{tabular}

Table 1: Reported usability problem

\begin{tabular}{|c|c|c|c|}
\hline & Map & category & examples \\
\hline a & GM & $\begin{array}{l}\text { selection of } \\
\text { operation }\end{array}$ & $\begin{array}{l}\text { I did not know where I should click in order to display a screen in which I can input } \\
\text { start and destination. }\end{array}$ \\
\hline b & GM & $\begin{array}{l}\text { operation/ } \\
\text { perception load }\end{array}$ & Unlike paper maps, it is not easy to look at same place again and again on web maps. \\
\hline b & GM & $\begin{array}{l}\text { operation/ } \\
\text { perception load }\end{array}$ & $\begin{array}{l}\text { trying to use the function, I try to set my home as start in order to avoid complication } \\
\text { but this function can not be used only after login. Then, I stopped to do so. }\end{array}$ \\
\hline b & GM & $\begin{array}{l}\text { operation/ } \\
\text { perception load }\end{array}$ & $\begin{array}{l}\text { With fingers, fine adjustments are possible as I expected on smartphones, but it was } \\
\text { difficult to adjust with this (a mouse) }\end{array}$ \\
\hline b & GM & $\begin{array}{l}\text { operation/ } \\
\text { perception load }\end{array}$ & $\begin{array}{l}\text { When I would like to see how far is it from the start to the destination (at very small } \\
\text { scale) surrounded detail information could not be seen, whereas in close up scale I can } \\
\text { not measure the distance. This gave me a trouble. }\end{array}$ \\
\hline b & SM & $\begin{array}{l}\text { operation/ } \\
\text { perception load }\end{array}$ & It is nuisanse to wait for map loading after a click \\
\hline C & LHM & $\begin{array}{c}\text { practical } \\
\text { interpretaiton }\end{array}$ & $\begin{array}{l}\text { the hazard map portal run by the ministry of land, infrastructure, and transortation does } \\
\text { not display flood information of second-grade rivers, which were controled by local } \\
\text { government. People who do not know this might overlook risk of flood }\end{array}$ \\
\hline
\end{tabular}

Table 2: Example of usability problems. Note : GM: Google map, LHM: Layered hazard map, SM: Security map

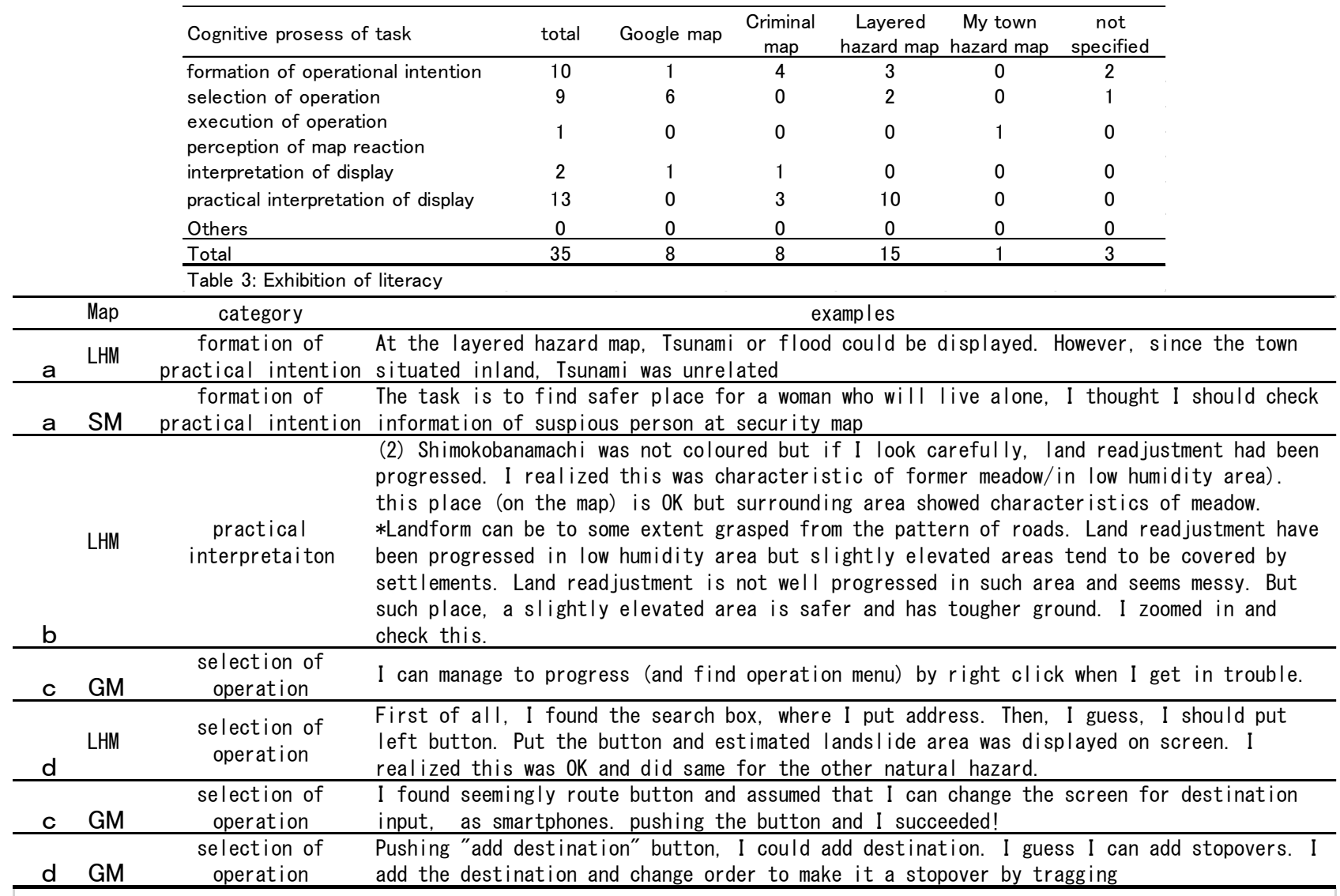

Table 4. Example of literacy. Note : GM: Google map, LHM: Layered hazard map, SM: Security map 


\section{Discussion}

\subsection{Usability of online maps}

It has been pointed out that most of the usability problems relate to search (e.g., Nivala, Brewster, \& Sarjokoski, 2008). This was replicated in the current study. Manyproblems were pointed out for the route search in Google Map, which was seeming difficult to find (Table 2, a). With Google Map, the route search menu does not appear by default, and some of the participants reported that they wondered how to find the search. This might not be serious since all of them could solve route search problems. They solved the problems by using reaction of the map. However, seemingly difficulty of operation could be a problem for those who evaluated themselves as not good at using maps and might be a potential barrier to using online maps.

Problems categorized as operation and perception load were also reported. They were: requiring a lot of work, difficulty of map use, problems arising from scale change, concealment problem, and delay of map load (Table 2, b). Although users can see several maps in turn by using the tabs of browsers or the scale can be changed as users wish with online maps, when going back from another tab, the center of the map sometimes changes and inactive tabs are likely to be forgotten. Ironically, utility of tabs or scale change makes users realize the subjective inconvenience.

Not a few problems were reported for "Practical interpretation." Even though results corresponding to an operation displayed smoothly, the displays might sometimes be irrelevant to the context of the users. This might lead to inappropriate interpretation for the real world practice. Among those, the most problematic one was that only flooded areas of first-grade rivers were displayed by default in the Layered hazard map (Table 2, c), which led to the result that 2) Shimokobanamachi was not colored as a flooded area. The researchers of natural disasters concluded that they suspected there might be a flood, but that was not displayed, whereas three students selected 2) as a safe site to live although some students felt suspicious. By the route search task with Google Map, the usual first hit for "Yoro hot spring" was a place with the same name in Gifu Prefecture, which is far from Chiba Prefecture, if users did not add a supplemental search word like "Chiba." Two of the students did not realize the irrelevant hit and continued until they were alerted by the experimenter. Both of the problems derived from irrelevant display for the real-world problem solving. Smooth result of the search might make the irrelevancy more difficult to notice and lead to a potentially serious mistake by users.

\subsection{Literacy}

Exhibition of literacy was observed at "formation of operational intention," and "practical interpretation." Operational intention is intention which can be operated on online maps. For formation of such intention, it is necessary to transform statements given in natural language such as "route including stopover(s) from JR Chiba Station to Yoro hot spring" or "safe living sites" to a statement which is operable on online map. Examples of "formation of operational intention" was observed at the time when the user focused on natural disasters which should be checked in the context of Gunma Prefecture, or focused on crimes which are likely to be committed against young women (Table 3, a). In the step of "practical interpretation," interpretation of hazard display using geographical knowledge, which link observable map features to unobservable geographic characteristics, was observed. Especially, the researchers held a strong suspicion against the display which did not show the flood areas in 2) Shimokobanamachi by inferring the origin of the settlement and micro topography of the settlement from patterns of the road displayed on the map (Table 3, b). Similar use of knowledge was observed among students, like "as a river is near, I wonder why this place is not colored for flood," or "a flood would occur at a river. So I should not get near at the time of heavy rainfall," but they did not exclude 2) from the answer. How the difference in judgment between the researchers and the students occurred is an interesting question for future research from the viewpoint of status of knowledge.

While domain-specific geographical knowledge was used for "practical interpretation," general knowledge of personal computers or software or strategies referring to reactions of online maps were observed in selecting operation. Interactive online maps usually react to the operation of users. If the reaction is relevant to the operational intention, problems can be solved relatively easily by following the reaction of the online maps even though the necessary operation may not be clear at first. Online map design corresponding to the literacy may contribute to improving the usability of online maps.

Repeated zooming in and out were widely observed among participants which was not reported verbally. Some natural disasters displayed only in limited areas even if hazard display button was clicked. The users repeated zoom in and out in order to check the change of display and check the relevance of display. This is a kind of literacy which is specific to online maps.

\subsection{Literacy and usability}

The literacy complemented usability and higher order usability sometimes decomposed into lower order usability and literacy. For example, if a hazard map does not display flooded areas relevantly, one might be deceived by the irrelevant display if one does not have the literacy to interpret the display, but if one has the literacy to critically examine appropriateness of the display, s/he can form an intention to find the operation to attain a relevant display, and the problem shifts to a lower order usability problem. In fact, the interview revealed that the same reaction of online maps was regarded as a usability problem by some participants, while it was regarded as an opportunity to use literacy by other participants.

\section{Conclusion}

From the point of view of real-world problem solving, usability problems still remained in online maps which are otherwise easy to understand and operate. At the same time, users exhibited literacy which is based on domain-specific 
existing knowledge or knowledge of personal computers/software in order to solve problems. The literacy was mainly used for selecting an operation in the task like route search, while the literacy to link the real world to operation of display of online maps was observed in the safety task. For effective use of online maps, development of literacy which is complementary to usability is important in addition to improvement of usability of online maps. The important finding of the current research is to find the framework for this viewpoint.

\section{Acknowledgements}

This study is supported by Grant-in-Aid for Scientific Research (17H00839).

\section{References}

Aldrich, F., and Sheppard, L. (2000). Graphicacy: The fourth 'R'? Primary Science Review, 64, 8-11.

Bishop, B. W., Haggerty, K. C., and Richardson, B. E. (2015). Usability of E-government mapping applications: lessons learned from the US National Atlas. International Journal of Cartography, 1, 134-150.

Çöltekin, A., Heil, B., Garlandini, S. and Fabrikant, S. I. (2013). Evaluating the effectiveness of interactive map interface designs: A case study integrating usability metrics with eye-movement analysis. Journal Cartography and Geographic Information Science, 36, 517.

Harada, E. (1997). Study of the artifacts from view point of human. Tokyo: Kyoritsu Shuppan (in Japanese).

Murakoshi, S. (2006). Digital map use and evaluation from university students. Map, Journal of the Japan Cartographers Association, 44, 9-14 (in Japanese).

National Research Council (2006). Learning to think spatially. Washington D.C.: The National Academies Press.

Nivala, A.M., Brewster, s., and Sarjokoski, L.T. (2008) Usability evaluation of web map sites. The Cartographic Journal, 45(2): 129-138.

Norman, D. A. (1986). Cognitive engineering. In D. A. Norman and S. W. Draper (eds.), User centered system design. Hillsdale, NJ: Lawrence Erlbaum Associates.

Okamoto, K. (2002). Survey of use status of maps. In Report of Grant-in-Aid for Scientific Research B(1)H1112: Study on communication of spatial information and spatial mobility using maps (Wakabayashi, Y.), 5-22 (in Japanese).

Saeki, Y. (1988). Information processing of human and machine: Introduction to cognitive engineering. In $\mathrm{K}$. Takeuchi (ed.) Meaning and information. Tokyo: University of Tokyo Press (in Japanese).

Voldan, P. (2011). Usability testing of web mapping portals. Geoinformatics FCE CTU, 5, 57-65.

Wakabayashi, Y. (2003). The pattern of map use by university students and factors affecting its variation. Map, Journal of the Japan Cartographers Association, 41, 26-31 (in Japanese).
Wakabayashi, Y. (2018). Theory of map revolution: The future of geographical information and human. Tokyo: Sogensha (in Japanese).

Zenrin (2018). Survey of use status of maps. Zenrin (in Japanese). 